\title{
WHAT CLINICAL COMPETENCIES DO WE EXPECT FROM PHYSIOTHERAPY STUDENTS AT THE UNIVERSITY OF THE WESTERN CAPE?
}

\begin{abstract}
The purpose of this study is to identify the clinical competencies that are expected of physiotherapy students at the University of the Western Cape. A list of ten categories of clinical competencies was first compiled from the literature and adminisTYSON SIMUZINGILI SEYI LADELE AMOSUN tered to 2 lecturers, 5 clinical supervisors and 10 final year students, to elicit their perspectives of expected clinical competencies. Based on the outcome of this, a list of eight categories of competencies was administered to 7 lecturers, 50 clinical supervisors and 31 final year students. Participants were requested to rank the competencies in order of what was considered to be essential. The analysis of 79 responses revealed similarities among lecturers, clinical supervisors and students in the ranking of three competencies, but disparities in the ranking of five competencies. Reasons for the disparities, and the impact of the disparities on students are discussed. Further research is recommended to identify the reasons for the disparities.
\end{abstract}

\section{KEY WORDS: CLINICAL COMPETENCIES, CLINICAL SUPERVISORS, LECTURERS, STUDENTS, RANKING}

\section{INTRODUCTION}

A major challenge in physiotherapy education is the task of enabling students to develop clinical competencies (Potts, 1996). Physiotherapy students are expected to complete certain hours of supervised clinical practice which include a considerable amount of competency-based assessments often carried out by the lecturer and the clinical supervisor. Assessment of the competencies presents a challenge to students, lecturers and clinical supervisors because of the complexities of the clinical environment (Oldeadow, 1996). Lecturers are expected to determine which behaviours constitute a clinical competence that students should have acquired during the particular clinical block. Clinical supervisors are expected, through direct and indirect supervision, to enhance students' levels of competency. Since there are considerable numbers of

\section{CORRESPONDENCE:}

Prof Seyi Ladele Amosun Department of Physiotherapy, University of the Western Cape Private Bag X17, Bellville, 7535

Tel: (021) $9592542(w)$ (021) 9030476 (h) clinical supervisors, their perspectives of expected clinical competencies vary (Nayer, 1995; Cross \& Hicks, 1997). The lack of explicit criteria for expected clinical competencies results in differences of opinion on what is expected of students. This leads to great dissatisfaction among students (Amosun \& Dantile, 1996; Cross \& Hicks, 1997).

Disparities in opinion of expected clinical competencies have been attributed to differences in definition of competence (Hager \& Gonczi, 1996). In the past, assessment of professional competence centred mainly on performance. Later, professional competence was viewed as the possession of desirable attributes, including knowledge, skills and abilities (such as problem solving, analysis, communication, pattern recognition), and appropriate attitudes in the context of a chosen set of professional task. It is believed that concentrating on the performance of the task without due regard for the attributes is the prime reason many professionals lapse into a narrow view of competence.

Newble (1992) defined clinical competence as the mastery of a body of relevant knowledge and the acquisition of a range of relevant skills which include interpersonal, clinical and technical components. Southgate (1994) also defined clinical competence as the ability and the will to select and perform relevant clinical tasks in the context of the social environment, ensuring that health problems of individuals and groups are resolved in an efficient, effective, economic and humane manner. Similarly, in an undated document, the Professional Board for Physiotherapy defines physiotherapy competence as a significant behaviour or activity performed in a specific setting or environment to a specified standard (South African Medical and Dental Council).

Students are expected to demonstrate "knowledge", "skills" and "attitudes" compatible with competent clinical practice (Cross \& Hicks, 1997). These three domains are subdivided further into more detailed categories. Aston-Mc Crimon (1986) identified eleven categories of competencies namely (in ranking order of importance) professional ethics and attitudes, communication skills, personal qualities, treatment skills, evaluation of patient, and planning of treatment. Other categories include implementation of client care services, research skills, professional 
growth, administrative skills and theoretical knowledge. Another study identified five categories namely communication skills, patient assessment, treatment planning, performance of treatment, and professional behaviour (Sanford et al, 1993). Declute and Ladyshewsky (1993) identified seven categories namely patient assessment, treatment planning, implementation of treatment plan, communication with patient/family, management skills, documentation and professional behaviour. The Professional Board for Physiotherapy also identified eleven categories of competence. These are professional behaviour and attitudes, communication, examination and assessment, designing a treatment programme, and utilisation of therapeutic procedures. Other categories are counseling, developing educational/ instructional services, management and administration, research, consultation, and developing physiotherapy services as part

TABLE I: LIST OF EXPECTED CLINICAL COMPETENCIES (Loomis, 1985; Declute \& Ladyshewsky, 1993; Sanford et al, 1993)

\section{Categories of competencies}

Implementation of treatment

Programme planning ${ }^{\circ}$

Patient assessment

Communication skills

Documentation $^{b}$

Professional behaviour

Theoretical knowledge

Safety of the patient

Professional growth

Management skills related to direct patient care

\section{Components of the competencies}

Treatment techniques, performance of effective treatment and progression of treatment techniques.

Planning treatment services, identifying primary problems and inclusion of the family in the planning process.

General assessment procedures including history taking, performance of assessment, selection of appropriate assessment procedures and re-assessment.

Art of listening, verbal and non verbal communication, confidentiality of patients' information and explanation of treatment of the patient.

Recording, correct charting of information, and writing progress notes.

Socially commendable qualities, personal characteristics and professional ethics, and appearance.

Technical knowledge, knowledge of basic sciences such as anatomy, physiology, pathology, and psycho-social influences.

Awareness of safely factors, safe handling techniques, and modification of treatment in the interest of safety.

Contributing and participating in research related activities and further education.

Managerial and administrative activities related to the well-being of the patient, adherence to operational procedures.

"Incorporated later into "Implementation of treatment plan" for the second phase of study.

"Incorporated later into "Communication skills" for the second phase of study.

of a health care plan.

The University of the Western Cape (UWC) offers a four-year BSC degree programme in physiotherapy. Third and fourth year students spend six weeks and four weeks respectively rotating through the following clinical blocks spread over the two years:- spinal unit, intensive care unit, community rehabilitation, geriatrics, paediatrics, neuro-muscular disorders, and a general block consisting of orthopaedics, respiratory and neurological disorders. Lecturers are primarily responsible for assessing the clinical competence of the students at the end of each block (occasionally assisted by clinical supervisors) and during clinical examination.

Currently, different aspects of the physiotherapy education programme in UWC are being evaluated in order to ensure quality. An earlier study on burnout among physiotherapy students reported that third and fourth year students found the evaluations of clinical competencies very stressful (Amosun \& Dantile, 1996). Personal observations revealed that the situation was further worsened by the comments of external examiners who insinuated that failure in one clinical examination was indicative of poor clinical competence. The study concluded that it was necessary to identify the stressful factors and make necessary adjustments. As a starter, the current study was carried out to identify the clinical competencies expected of physiotherapy students at UWC. Earlier studies were based essentially on the perspectives of physiotherapy lecturers and clinical supervisors only (Onuoha, 1994), but final year students who have been exposed to clinical education for at least two years, were included in this study sample. Therefore, the objectives of this study were:

1. To identify the clinical competencies physiotherapy lecturers 
expected of students.

2. To identify the clinical competencies clinical supervisors expected of students.

3. To identify the clinical competencies physiotherapy students presumed were expected of them.

4. To compare the responses of lecturers, clinical supervisors and students.

\section{METHODOLOGY}

The study was conducted in two phases. Using the Delphi technique, the aim of the first phase was to develop a survey instrument to obtain the clinical competencies that were expected of physiotherapy students. Initially, a list of ten categories of expected clinical competencies was compiled from the available literature (Loomis, 1985; Declute \& Ladyshewsky, 1993; Sanford et al, 1993). The competencies pertained to the knowledge, skill and attitude necessary for the delivery of safe and optimal patient care (Table I). The list of competencies recommended by the Professional Board for Physiotherapy in South Africa was not used in the first phase because the document containing the list was undated. The developed list of competencies was given to a convenient sample of five clinical physiotherapists, ten 4 th year students and two lecturers (from UWC). Participants were asked to indicate agreement or disagreement with the items on the list, and to add to the list if necessary.

In view of the responses in the first phase, a list of eight categories of expected competencies was developed for the second phase of the study (Table II). The list was administered to lecturers $(n=7)$ and 4th year physiotherapy students $(\mathrm{n}=31)$ at UWC, as well as clinical supervisors $(n=50)$ identified by heads of physiotherapy departments within the Cape Metropolitan area. The participants were asked to rank the categories of expected
TABLE II: RANKING OF CLINICAL COMPETENCIES BY LECTURERS, CLINICAL SUPERVISORS AND STUDENTS.

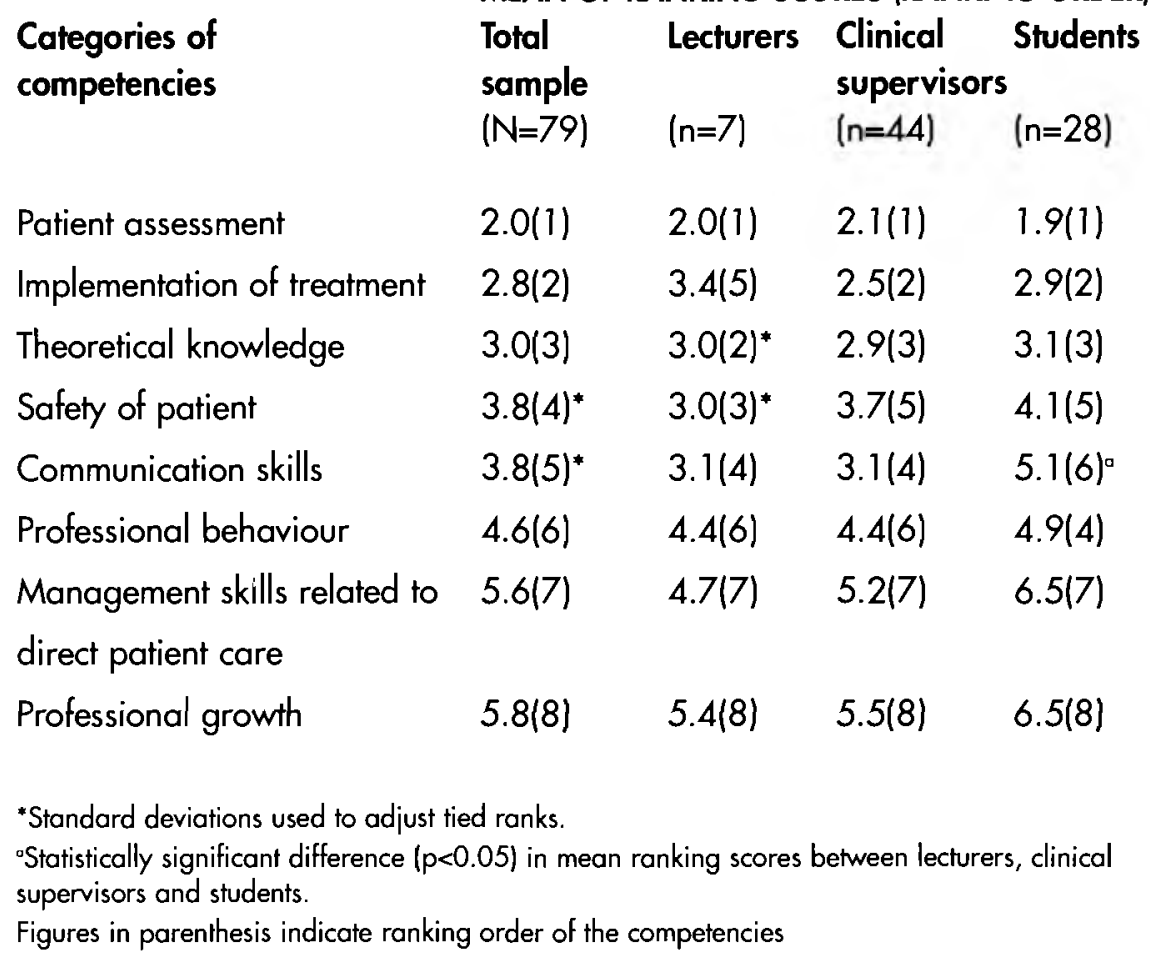

\section{TABLE III: RANKING OF CLINICAL COMPETENCIES ACCORDING TO YEARS OF CLINICAL EXPERIENCE.}

\section{Categories of competencies}

Patient assessment

Implementation of treatment

Theoretical knowledge

Safety of patient

Communication skills

Professional behaviour

Management skills related to

direct patient care

Professional growth
MEAN OF RANKING SCORES (RANKING ORDER) Total 2-5 years $6-10$ years $>10$ years sample $(N=79) \quad(n=59) \quad(n=8) \quad(n=12)$

$\begin{array}{llll}2.0(1) & 2.0(1) & 1.5(1) & 2.6(1) \\ 2.8(2) & 2.6(2) & 1.6(2) & 4.3(5)^{\circ} \\ 3.0(3) & 3.0(3) & 2.0(3) & 3.5(4) \\ 3.8(4)^{*} & 4.0(4) & 3.0(5) & 3.2(3) \\ 3.8(5)^{*} & 4.1(5) & 2.9(4) & 3.2(2) \\ 4.6(6) & 4.6(6) & 3.3(6) & 5.4(6) \\ 5.6(7) & 6.0(7)^{*} & 4.5(8) & 5.6(7)\end{array}$

$5.8(8) \quad 6.0(8)^{*} \quad 4.3(7)$
*Standard deviations used to adjust tied ranks.

'Statistically significant difference $(p<0.05$ ) in mean ranking scores between lecturers, clinical supervisors and students.

Figures in parenthesis indicate ranking order of the competencies 
clinical competencies on an eightpoint scale, ranging from 1 (most essential) to 8 (least essential). The participants were informed of their rights to refrain from taking part in the study. The questionnaire was completed anonymously to maintain confidentiality.

The data of seventy nine responses (7 lecturers, 28 students and 44 clinical supervisors) were analysed using descriptive statistics. The mean score for each clinical competence was determined. Using the mean scores, the competencies were ranked and standard deviations were used to adjust tied ranks. A mean skewed towards 1.0 indicated a competence considered highly essential. One way analysis of variance (ANOVA) was used to test the differences in the mean scores between the three groups of participants.

\section{RESULT}

The total group of participants ranked the competency, patient assessment, as the most essential clinical competence expected of physiotherapy students (Table II). The same table presents the order in which the clinical competencies were ranked separately by lecturers, clinical supervisors and students. Between the three groups of participants, a significant difference $(p<0.05)$ was observed in the mean rating scores for communication skills.

All the participants, irrespective of the years of clinical experience (2-35 years), ranked patient assessment as the most essential clinical competence expected of physiotherapy students (Table III). However, participants with more than 10 years clinical experience significantly $(p<0.05)$ scored implementation of treatment lower than participants with less experience.

\section{DISCUSSION}

The primary purpose of this study was to identify the clinical compe- tencies that are expected of physiotherapy students at UWC. The secondary purpose was to compare the ranking of the competencies by lecturers, clinical supervisors and students. The list of the eight clinical competencies developed at the end of the first phase of this study was comparable to the lists of clinical competencies developed in earlier studies (Aston-Mc Crimon, 1986; Declute \& Ladyshewsky, 1993) and by the Professional Board for Physiotherapy.

The study also revealed that there were similarities among lecturers, clinical supervisors and students in the ranking of three competencies. All the participants agreed that patient assessment was the most essential competence, while management skills related to direct patient care and professional growth were considered the least essential of expected competencies. The ranking of patient assessment as the most essential competence is in agreement with the outcome of the study by Declute \& Ladyshewsky (1993).

There were disparities in the ranking of five competencies. Clinical supervisors and students agreed that, after patient assessment, the next competence expected of students was implementation of treatment. However lecturers gave a less than average ranking to this competence. For lecturers, theoretical knowledge was next in ranking. This difference between the expectations of lecturers and clinical supervisors could have been influenced by their perceived roles in clinical education. Lecturers are usually expected to assist students acquire theoretical knowledge considered to be the basis for development in clinical practice (Margetson, 1996), while clinical supervisors are expected to facilitate students' learning in the clinical environment (Onuoha, 1994).

Another noticeable difference was in the ranking of the patients' safety.
Surprisingly, clinical supervisors ranked safety of patients lower than lecturers. In personal communications with the authors, clinical supervisors often expressed great concern about the safety of patients allocated to students. Is the ranking by clinical supervisors a reflection of greater confidence in students to ensure the safety of patients? It was also observed that the students ranked professional behaviour higher than lecturers and clinical supervisors, while the lecturers and clinical supervisors ranked communication skills higher than the students. The possible reasons for such ranking could not be deduced immediately.

In comparison with earlier studies reporting on the perspectives of lecturers, clinical physiotherapists and students, there are similarities in expected competencies but some differences in the ranking of the competencies. Aston-Mc Crimon (1986) reported that lecturers ranked communication skills very low in order of importance, compared to an average ranking in this study. AstonMc Crimon (1986) also reported on a group of clinical physiotherapists ranking highly professional behaviour, while Sanford et al (1993) reported on another group of clinical physiotherapists who gave an average ranking to the same competence. However in this study, clinical supervisors gave a below average ranking to professional behaviour. A study on physiotherapy students in Australia considered appropriate theoretical knowledge a more essential competence than implementation of treatment (Oldmeadow, 1996). In this study, the students ranked implementation of treatment higher than theoretical knowledge. It is worthwhile to identify the reasons for these disparities.

Analysis of the responses based on years of clinical experience of participants also showed differences in ranking of expected competencies. Next to patient assessment, partici- 
pants with not more than 10 years of clinical experience ranked implemention of treatment and theoretical knowledge as the most essential competencies. However, participants with more than 10 years of clinical experience ranked communication skills and safety of patients as the most essential competencies. It seems what clinical supervisors and lecturers expected of students was influenced by years of clinical experience. This can only lead to frustration among the students.

Particularly important to the health care professions is student satisfaction with clinical education because this component of the curriculum has an impact on professional attitude, career commitment, and retention (Stith et al, 1998). The disparities observed in the perspectives of the participants in this study may generate great dissatisfaction among students with clinical education. Between clinical supervisors and students, there was agreement in the ranking of six competencies. Between lecturers and clinical supervisors, there was agreement in the ranking of five competencies. Between lecturers and students, there was agreement in only three competencies. Therefore, at clinical examinations or end of clinical block evaluations conducted by lecturers, the disparities in the perspectives of the lecturers and the students could lead to frustrations among students. This supports a remark from students expressed earlier that they find the evaluation during the clinical blocks very stressful (Amosun \& Dantile, 1996). The disparities in the perspectives of the clinical supervisors and the students could also frustrate students' learning efforts in clinical education. Therefore, an agreement among lecturers and clinical supervisors on the clinical competencies expected of students, and the ranking of the competencies, will contribute significantly to alleviate the frustration of the students. It will also assist students to evaluate their own progress in learning and will make their learning meaningful and purposeful.

\section{LIMITATIONS OF THE STUDY}

The outcome of this study would have been more relevant if the participants in the second phase were asked to rank the list of competencies expected by the Professional Board for Physiotherapy in South Africa. However the list of competencies developed for this study compare favourably with the competencies expected by the Professional Board for Physiotherapy. Also, the study did not identify the reasons why the participants ranked the competencies in a particular order.

Restricting this study to participants involved in only one of the eight physiotherapy education programmes in South Africa makes it impossible to generalise the data obtained. It is recommended that further research be carried out in other physiotherapy education programmes to identify if there are disparities in expected clinical competencies, and the reasons for such disparities.

\section{CONCLUSION}

As physiotherapy students are being prepared to face the challenges of the profession, required clinical competencies should be clearly defined. There is a need for the lecturers and the clinical supervisors at UWC to come to agreement on the clinical competencies, as well as the ranking of the competencies, expected of physiotherapy students.

\section{REFERENCES}

Amosun SL \& Dantile ND. 1996 Evaluating physiotherapy education at the University of the Western Cape - Are we graduating physiotherapists with the burnout syndrome? South African Journal of Physiotherapy 52:69-72

Aston-Mc Crimon E. 1986 Analysis of the rating of competencies used in physiotherapy. Physical Therapy 66:954-960
Cross V \& Hicks C. 1997 What do clinical educators look for in physiotherapy students? Physiotherapy 83:249-260

Declute J \& Ladyshewsky R. 1993 Enhancing clinical competence using a collaborative clinical education model. Physiotherapy 73:683689

Hager P \& Gonczi A. 1996 What is competence? Medical Teacher 18:15-18

Loomis J. 1985 Evaluating clinical competence of physical therapy students - Part 2: Assessing reliability, validity and usability of a new instrument. Physiotherapy Canada $37: 91-98$

Margetson D. 1996 Beginning with essentials: Why problem-based learning begins with problems. Education for Health 9:61-69

Nayer M. 1995 The assessment of clinical competency: An overview and preliminary report of Canadian physiotherapy programs. Physiotherapy Canada 47:190-199

Newble DI. 1992 Assessing clinical competence at the undergraduate level. Medical Education 26:506-511

Oldmeadow L. 1996 Developing clinical competence: A mastery pathway. Australian Journal of Physiotherapy 42:37-44

Onuoha A. 1994 Effective clinical teaching behaviours from the perspective of students, supervisors and teachers. Physiotherapy 80:208-212

Potts J. 1996 Physiotherapy in the next century: Opportunities and challenges. Physiotherapy 82:150-155

South African Medical and Dental Council, The Professional Board for Physiotherapy. Training for physiotherapy students Competency profile and physiotherapy task list.

Sanford J, Stratford P, Solomon P. 1993 Clinical evaluation - Physiotherapists ranking of competencies. Medical Teacher 15:369-377

Stith JS, Butterfield WH, Strube MJ, Duesinger SS, Gillespie DF. 1998 Personal, interpersonal, and organizational influences on student satisfaction with clinical education. Physical Therapy 78:635-645

Southgate L. 1994 Freedom and discipline: Clinical practice and assessment of clinical competence. British Journal of Clinical Practice 44:87-92 